\title{
IDÉIAS
}

que a Reforma venha contribuir para a superação desses vicios?

Acredito que só se obtém algum sucesso na modernização da administração pública, quando se atua na cabeça das pessoas. Mudanças culturais só se consumam em mais de uma geração. Não será mais fácil mudar estruturas do que o comportamento das pessoas? Espero que a Reforma Administrativa que ora se inicia procure mobilizar, através da educaçāo, da participaçāo e do treinamento, todos os servidores, notadamente os de nivel gerencial, para o esforço de construção de uma nova administração pública. Mas que seja capaz também de mobilizar a sociedade brasileira no sentido de maior participação e controle das aç̋es dos administradores. É preciso haver congruência entre o discurso e as práticas vigentes. $\mathrm{O}$ discurso oficial da nova república estabelece o mérito e a competência do servidor como valores fundamentais que precisam ser fortalecidos. E na prática, o que estamos fazendo para converter a retórica em açå?

\begin{tabular}{|c|}
\hline Ao longo deste meio \\
século, têm variado \\
as prioridades e as \\
premissas que servem \\
de fundamento a \\
Reforma. Mesmo assim, \\
ocorrem idéias muito \\
semelhantes e até o \\
sistema do mérito foi \\
a pedra angular da \\
reestruturação que o \\
Estado Novo tentou \\
dos anos trinta até \\
meados dos quarenta.
\end{tabular}

Espero que o Governo venha efetivamente a desempenhar esforços sistemáticos e permanentes para a formaça de quadros mais comprometidos com os valores de austeridade, probidade e uso adequado dos recursos públicos, essenciais a uma administração pública que se quer democrática.

\section{Fórum debate ética para o Serviço Público}

\section{Dielai Carvalho Pereira (*)}

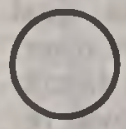

Fórum de Debates sobre as Diretrizes da Refoma da Administração Pública Federal, promovido nos dias 13 e 14 de marco, pelo $\mathrm{Mi}$ nistério da Administração, foi um marco importante no processo brasileiro de reorganização institucional, que certamente antecipa o grande debate nacional em torno da Constituição.

A tônica predominante nas reflexỏes foi o novo comportamento do cidadão brasileiro, despertado com o programa de estabilidade econômica do Presidente Sarney. Sob diferentes ângulos e fundamentaçðes ou conceitos, as importantes contribuiçðes trazidas ao debate nacional por Carlos Lessa, Clóvis Ferro Costa, Deputado Irajá Rodrigues, Deputado José Gregori, Ministro Bento Bugarin, Jorge Hori, Piquet Carneiro, Ministro Xavier de Albuquerque, Senador Severo Gomes e pelos demais debaledores somaram-se às propostas da Câmara I, da Comissão Geral da Reforma da Administração Pública Federal, constituida pelo Ministro Aluizio Alves, em outubro de 1985.

Alcançou-se, nessa primeira etapa, o objetivo do Fórum, com ampla discussão das idéias formuladas no âmbito da Câmara I, encarregada de sugerir a estratégia governamental de mudança, visando a dotar o serviço público de condições institucionais, administrativas e gerenciais mais adequadas ao processode democra tização que o Pais vem atravessando.

Os temas de debate - Funções do

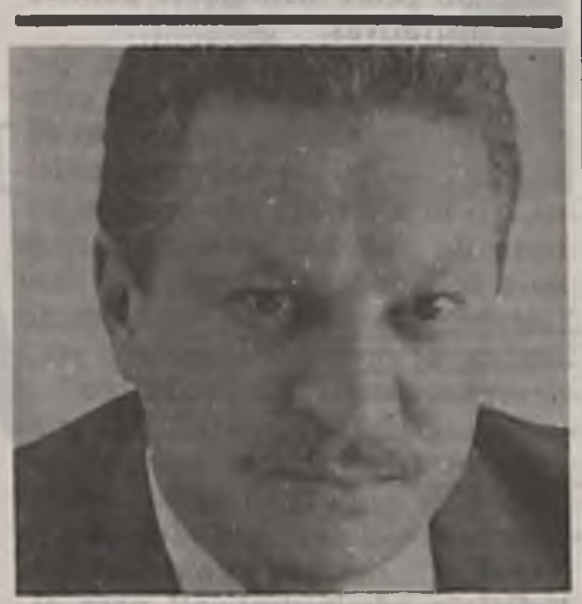

Estado e o papel da administração pública, Competências do Poder Legislativo e do Poder Executivo em matéria de descentralização; gestão, avaliaça e controle da administracão - proporcionaram oportunidade para análise dos instrumentos legais, ficando evidentes, em vários momentos, certos aspectos de coerência e efetividade que faltam aos meios atuais para conduzir aos objelivos que lhes deram origem.

Selecionar desse debate os pontos mais importantes que foram objeto de exame não é tarefa fácil. Constituem a base sobre a qual os técnicos, administradores, polítiços e legisladores trabalharão, com o intuito de criar o ambiente propicio ao pleno exercício dos direitos de cidadania.

Entretanto, o esforco deve começar imediatamente e apesar da dificuldade de isolar e tratar principios e diretrizes dependentes de aspectos institucionais, politicos, sociais e es-

- Doutor em pedagogia e gerente de Treinamento e Desenvolvimento de Recursos Humanos da Secretaria de Modernizaçáo e Reforma Administrativa do Ministério da Administraçáo 
tratégicos, nos propomos a somar esforcos para essa arquitetura.

O primeiro ponto, tratado no documento básico de discussão como "Principios Fundamentais da Reforma", foi enfatizado por Carlos Lessa ao abordar questoes referentes às "Funçóes do Estado e o Papel da Administração Pública Federal". Focalizando o tema sob o aspecto genético-constitutivo do panorama administrativo brasileiro, evidenciou o descompasso entre a modernidade do setor econômico e o desenvolvimento social e político. refletido pelas instituiçoes políticoadministrativas.

Argumentou Carlos Lessa que, apesar do intenso processo de urbanização que mudou, em poucas décadas, a feição do homem brasileiro, "o Brasil ainda nāo tem um sistema de partidos caracteristico de uma sociedade moderna, nāo tem padrōes maduros de organização sindical e, em conseqüência, o grau de representatividade é reduzido".

Essa situação, ressaltada por quase todos os painelistas, se coaduna, aliás, com o que chamou de "matriz fortemente autoritária do Estado Nacional", buscando uma chamada "eficácia administrativa" para alcançar os objetivos do Estado.

Ocorre, porém, que o "Estado brasileiro constituiu-se antes de sermos Nação completa, originando o fato de que as instituições nào nascem da vida social, mas são paridas pelo próprio aparelho do Estado"; nesse sentido, pode-se concluir que eståo a serviço deste c não da $\mathrm{Na-}$ çao. Como evidência, cita cxemplos públicos c notórios da incficiência do serviço público para exccutar os programas sociais do Governo, com custos elevadissimos e baixos resultados em face dos objetivos explicitos desses programas.

Outro aspecto referido ć a relutância sistemática dos brasileiros em participar da vida comunitária, ou seja, de relações de caráter primário, o que ocorre com mais nitidez entre os estratos sociais que mais se beneficiam dos padrōes do desenvolvimento econômico.

Com o Plano de Estabilização Econômica do Governo, "no momento em que o Presidente da República, num gesto de sabedoria exemplar, toma a decisåo de criar as condiçðes para que o nosso dinheiro passe a ser forte", abre-se novo panorama: o Estado, declarando-se impotente, per si, para exercer suas funções, recorre à população, à Nação, para criar as condiçōes de sucesso da reforma econômica. Esse fato originou, por extensão, um novo comportamento explicitado como cidadania. Na realidade, a recente transformação do homem brasileiro, de mero consumidor em fiscal, é apenas um inicio positivo, diga-se de passagem, para o comprometimento da população com o Estado e vice-versa.

Essa é, aliás, a proposta básica da Comissão Geral da Reforma, qual seja a de criar nova ética para o serviço público em que as ações da máquina estatal decorram de novas relações entre o estado e a sociedade.

\begin{tabular}{|c|}
\hline Apesar do intenso \\
processo de urbanização \\
que mudou, em pouças \\
décadas, a feicão do homem \\
brasileiro, o Brasil \\
ainda não tem um sistema \\
de partidos caracteristico \\
de uma sociedade moderna, \\
nào tem padrões maduros \\
de organização sindical e, \\
cm conseqüência, o grau de \\
representatividade é \\
reduzido. O Estado nasceu \\
antes da Nação (C. Lessa). \\
\hline
\end{tabular}

A partir de 28 de fevereiro, o que tambèm foi ressaltado por Lessa, criam-se as condições exógenas para que a Reforma Administrativa, advogada pelo Ministro Aluizio Alves, conte com bases verdadeiramente efetivas para a sua realização.

E evidente, como arremata o apresentador, que "o povo passou por uma mudança qualitativa e que irá passar a ser fiscal do desempenho das máquinas públicas" .

O Jurista Clóvis Ferro Costa abordou o tema situando a adminisIração pública como veículo do Estado, enfocando suas funções numa sociedade democrática, ora legitimadas pelo direito público, ora pelo direito privado, restando ao direito administrativo a formulação de re- gras especiais que convenham ao bom funcionamento do serviço público.

Fundamentando suas ponderações em consagrados autores, diz que não há por que aplicar regras especiais quando a administração resolve utilizar procedimentos do direito privado.

Esse talvez tenha que ser o grande acerto a proceder-se na administração pública federal, que transitou, desde a tentativa de modernização iniciada com o Decreto-lei 200, entre o direito público e o direito privado, sobretudo em questōes contratuais.

A propósito das últimas medidas do Governo, afirma: "neste momento, o direito público intervém para que as regras do direito privado na sua fluência normal, voltem a prevalecer sem as distorçōes da hiperinflaçåo e desmoralização da moeda, que é o valor de referência da vida moderna e da força dos contratos". Em outros termos, no momento em que a vida civil se desorganiza a tal ponto que as bases contratuais não são mais obedecidas, o Estado moderno tem o poder de agir como árbitro para coibir excessos e restabelecer o equilíbrio. Daí, a aparente contradiçăo de o Estado moderno intervir para liberar.

Além de exercer a administração e a justiça, definida a primeira como um conjunto de funçóes de natureza técnica, intelectual e juridica tendentes a alçançar o bem comum, pede-se ao Estado, cada vez mais, que proteja as atividades débeis. "De todos os lados chegam queixas e reclamos de uma minoria que não sabe mais sofrer ... O Estado é o grande suzerano: como o senhor de outrora, exige o serviço militar e o imposto, e com ele protege seus subordinados". Esse comentário, justificado pelos exemplos que dá e pelas próprias origens do Estado brasileiro, abordadas com as mesmas conotações do expositor anterior, sugere um recurso analítico, que, apesar de muito frequiente entre os teóricos da vida social e política, não foi mencionado uma única vez no Fórum: o Estado paternalista. Consciente ou insconscientemente, esse conceito se impōe por sua utilidade na explicitação de alguns compromissos ainda existentes entre o Estado e a Sociedade, cobrados 


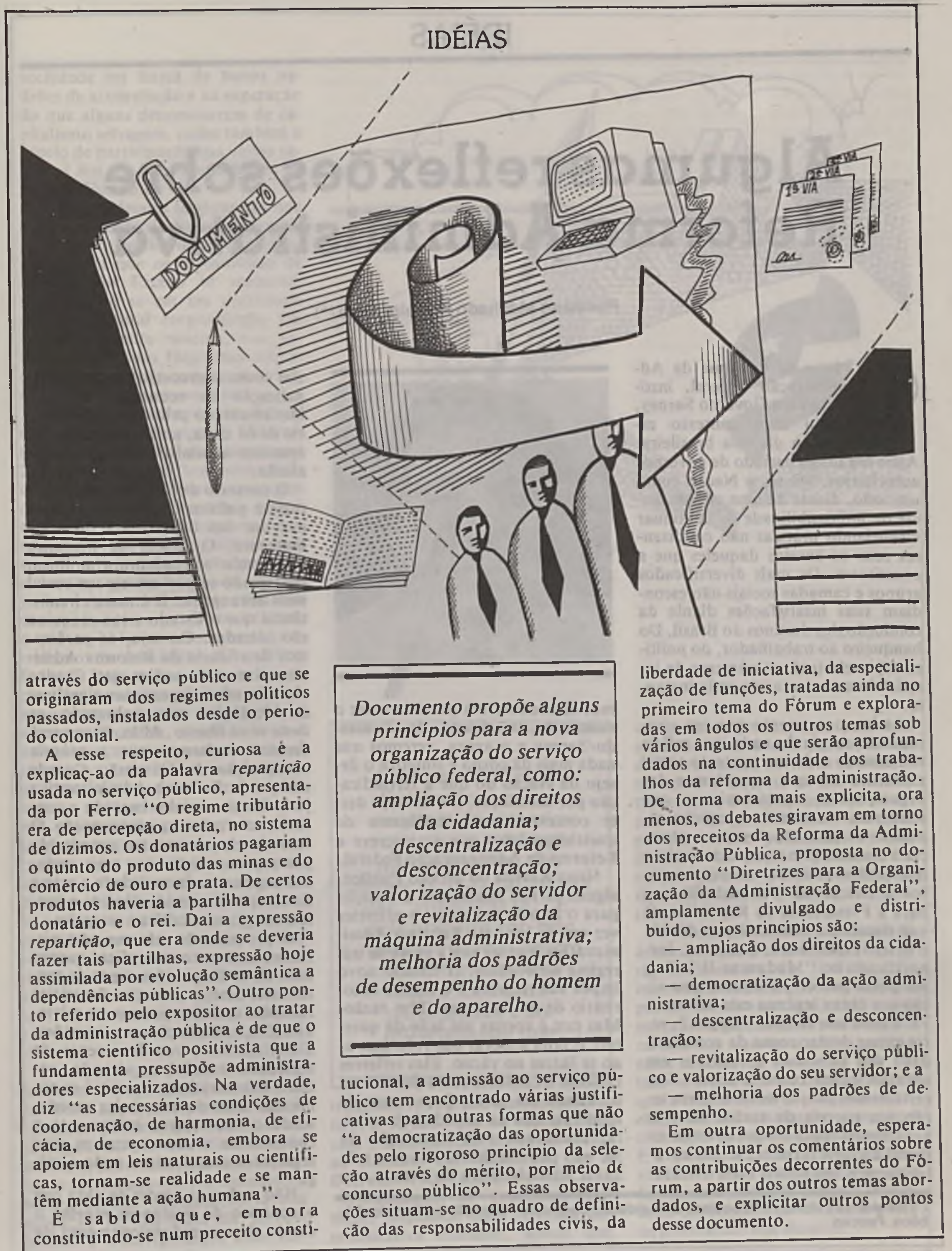

REVISTA DO SERVIÇO PÚBLICO 